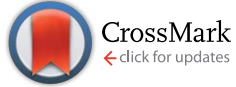

Cite this: RSC Adv., 2017, 7, 5679

\title{
Asymmetric synthesis of C-F quaternary $\alpha$-fluoro- $\beta$-amino-indolin-2-ones via Mannich addition reactions; facets of reactivity, structural generality and stereochemical outcome $\uparrow$
}

\author{
Chen Xie, ${ }^{a}$ Wanxing Sha, ${ }^{a}$ Yi Zhu, ${ }^{a}$ Jianlin Han, ${ }^{* a}$ Vadim A. Soloshonok ${ }^{b c}$ and Yi Pan ${ }^{a}$ \\ Reported herein is a new approach for the preparation of enantiomerically pure $\alpha$-fluoro- $\beta$-amino-indolin- \\ 2 -ones possessing tetrasubstituted fluorinated stereogenic centers. This method includes the \\ detrifluoroacetylative in situ generation of tertiary enolates followed by Mannich reaction with $\left(S_{s}\right)$ - \\ sulfinylimines. The operationally convenient conditions coupled with perfect diastereoselectivity and \\ functional substituent compatibility bode well for widespread application of this new synthetic method.
}

Received 3rd December 2016

Accepted 27th December 2016

solutions. Over the last several years, our group has contributed to this research area by the development of cyclic enolates 2 (eqn (2)) allowing preparation of structurally complex products possessing tetrasubstituted fluorinated stereogenic centers. ${ }^{13}$ The preliminary data on reactivity of tertiary enolates 2 with imines $^{14}$ revealed their moderate reactivity towards highly electrophilic $\mathrm{CF}_{3}$-imines 3 affording derivatives 4 featuring the structurally challenging quaternary C-F stereogenic center next to the amino functionality. While the preparation of compounds 4 was a noticeable methodological success, one might agree that rather excessive number of fluorine atoms and relatively high configurational liability of the $\mathrm{CH}$ stereogenic carbon, would limit the pharmaceutical application of compounds of type 4. Therefore, to realize the synthetic potential of this methodology we have to develop the corresponding Mannich addition reactions using common, non-

he development of detrifluoroacetylative, in situ generation of unprotected fluoro-enolates 1 (Scheme 1, eqn (1)). ${ }^{9}$ The initial study into the reactivity of enolates 1 using aldol, ${ }^{9,10}$ and Mannich ${ }^{10,11}$ reactions has revealed their generally promising synthetic potential along with some problematic aspects awaiting more focused research. For example, enolates 1 easily reacts with aldehydes ${ }^{9,10}$ and highly electrophilic, $\mathrm{CF}_{3}$-containing ketones ${ }^{12}$ and imines, ${ }^{11}$ while the reactions of 1 with unactivated $\mathrm{C}=\mathrm{O}$ and $\mathrm{C}=\mathrm{N}$ compounds still need more innovative

${ }^{a}$ School of Chemistry and Chemical Engineering, State Key Laboratory of Coordination Chemistry, Nanjing University, Nanjing, 210093, China. E-mail: hanjl@nju.edu.cn ${ }^{b}$ Department of Organic Chemistry I, Faculty of Chemistry, University of the Basque Country UPV/EHU, Paseo Manuel Lardizabal 3, 20018 San Sebastián, Spain. E-mail: vadym.soloshonok@ehu.es

'IKERBASQUE, Basque Foundation for Science Department, Alameda Urquijo 36-5, Plaza Bizkaia, 48011 Bilbao, Spain

$\dagger$ Electronic supplementary information (ESI) available: Detailed procedure and full characterization data, NMR spectra of product 11, 13, 14 and X-ray analysis data for 11bi. CCDC 1457060. For ESI and crystallographic data in CIF or other electronic format see DOI: 10.1039/c6ra27710a

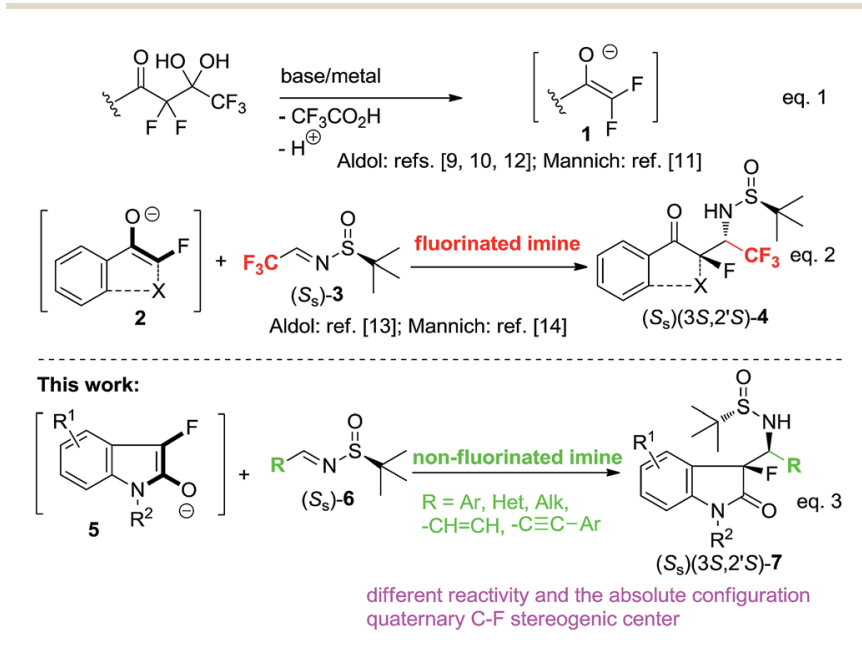

Scheme 1 Detrifluoroacetylative reactions with $\mathrm{CF}_{3}$-imines 3 and non-fluorinated imines 6 . 
fluorinated imines. In this work we report the very successful implementation of this goal, disclosing the Mannich reactions between 3-fluoroindolin-2-one derived enolates 5 (eqn (3)) and non-fluorinated aldimines $\mathbf{6}$. We demonstrate that these addition reactions occur with nearly perfect (>98:2) diastereoselectivity allowing preparation of the target quaternary $\mathrm{C}-\mathrm{F}$ / amino products in enantiomerically pure form.

Drawing from our experience in asymmetric Mannich additions $^{\mathbf{1 5}}$ and, in particular, dealing with unactivated imines, ${ }^{16}$ we selected non-enolizable and reasonably reactive imine 10a; also, bearing a trifluoromethylthio group - quite useful as the ${ }^{19} \mathrm{~F}$-NMR reference for monitoring the reaction outcome (Table 1). As was anticipated, the reaction of imine 10a conducted under the conditions (DIPEA, 2-Me-THF, -40 $\left.{ }^{\circ} \mathrm{C}\right)$ previously reported for the additions of $\mathrm{CF}_{3}$-sulfinylimine 3 (Scheme 1, eqn (2)), did not proceed at all. Lower reactivity of 10a was counteracted by the elevated reaction temperature. Thus, the addition was rather successful at $0{ }^{\circ} \mathrm{C}$, affording product 11aa with moderate yield, but with quite respected diastereoselectivity (entry 1). Building on this apparent progress, we proceeded with a thorough optimization of all reaction parameters starting with the base. A selection of examples presented in entries 2-7 convincingly demonstrates that the base's basicity is not of prime importance, while its steric bulk plays rather significant role. This observation can be rationalized considering the sterically congested nature of tertiary enolate and therefore, its sensitivity towards the steric bulk of the base used. Accordingly, for the further optimization study, we selected triethylamine (entry 2) which gave the finest combination of chemical yield and diastereoselectivity.

In the second round of the optimization experiments we focused on the properties of reaction solvent and its effect on

Table 1 Optimization of the reaction conditions for the detrifluoroacetylative Mannich addition reaction between $8 \mathrm{a}$ and imine (S) $-10 \mathrm{a}^{a}$

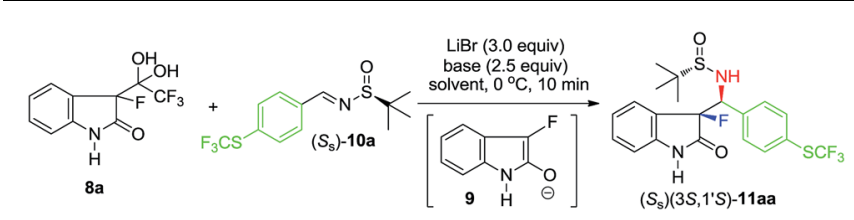

\begin{tabular}{lllll}
\hline Entry & Base & Solvent & Yield $^{b}(\%)$ & $\operatorname{Dr}^{c}$ \\
\hline 1 & DIPEA & THF & 54 & $97: 3$ \\
2 & $\mathrm{Et}_{3} \mathrm{~N}$ & $\mathrm{THF}$ & 88 & $97: 3$ \\
3 & $n \mathrm{Pr}_{3} \mathrm{~N}$ & $\mathrm{THF}$ & $<10$ & n.d. \\
4 & $n \mathrm{Bu}_{3} \mathrm{~N}$ & $\mathrm{THF}$ & $<10$ & n.d. \\
5 & $\mathrm{DABCO}$ & $\mathrm{THF}$ & 92 & $96: 4$ \\
6 & $\mathrm{DBU}$ & $\mathrm{THF}$ & 87 & $96: 4$ \\
7 & $\mathrm{TMEDA}$ & THF & 76 & $96: 4$ \\
8 & $\mathrm{Et}_{3} \mathrm{~N}$ & $2-\mathrm{Me}-\mathrm{THF}$ & 94 & $97: 3$ \\
9 & $\mathrm{Et}_{3} \mathrm{~N}$ & $\mathrm{CH} \mathrm{CN}_{3}$ & 89 & $>98: 2$ \\
10 & $\mathrm{Et}_{3} \mathrm{~N}$ & $\mathrm{DCM}$ & 80 & $>98: 2$
\end{tabular}

${ }^{a}$ Reaction condition: di-ketone hydrates $1 \mathrm{a}(0.6 \mathrm{mmol})$, sulfinylimine 10a (0.5 mmol), LiBr (156.3 mg, $1.8 \mathrm{mmol}$, 3.0 equiv.), base (1.5 mmol, 2.5 equiv.) in $5 \mathrm{~mL}$ solvent at $0{ }^{\circ} \mathrm{C}$ for $10 \mathrm{~min} .{ }^{b}$ Isolated yields of the major diastereomers. ${ }^{c}$ Determined by the ${ }^{19} \mathrm{~F}-\mathrm{NMR}$ analysis of the crude products. the addition reaction under study; the key representative results are presented in entries 8-10. For example, the application of 2Me-THF gave noticeably better yield (entry 8) as compared with that of the reaction conducted in THF. However, the diastereoselectivity in this reaction was still incomplete. In sharp contrast, the reactions conducted in $\mathrm{CH}_{3} \mathrm{CN}$ (entry 9) and DCM (entry 10) proceeded with nearly perfect stereochemical outcome. It should be mentioned that the used in this work notation (the diastereoselectivity of $>98: 2$ ) is a very conservative estimation, indicating that the NMR signals of other diastereomeric products were not observed in the reaction mixtures. Comparing the results obtained in $\mathrm{CH}_{3} \mathrm{CN}$ (entry 9) and DCM (entry 10), one may agree, that the former, providing higher chemical yield, was selected as the optimized solvent.

Next, we proceeded to study the substrate generality of this method. First, we decided to explore the reactivity and substituent effect of sulfinylimines $\left(S_{\mathrm{s}}\right)$-10a-r (Scheme 2) derived from aldehydes representing various structural types and classes.

Considering the 19 examples listed in Scheme 2, one might agree that the stereochemical outcome of the Mannich additions between di-ketone hydrates $\mathbf{8}$ and sulfinylimines $\left(S_{\mathrm{s}}\right)-\mathbf{1 0}$ is rather exceptional. In fact we failed to find an imine substrate reacting with less than $>98: 2$ diastereoselectivity. In terms of the chemical yields, the lowest value of $64 \%$ was obtained for product 11ab and, most likely, can be attributed to a slow reaction rate due to the steric shielding of the $\mathrm{C}=\mathrm{N}$ group in $10 \mathrm{~b}$ by the ortho-trifluoromethyl group. The highest, $97 \%$ yield, was registered for product 11aj, possessing para-nitro group. In general, for the compounds bearing electron-withdrawing substituents, the chemical yields were normally above $85 \%$, while unsubstituted 11ai and para-methyl products 11ae gave a bit lower ( $83 \%$ and $79 \%$ ) yields. The observed tendency is apparently a function of the electrophilicity/reactivity of the

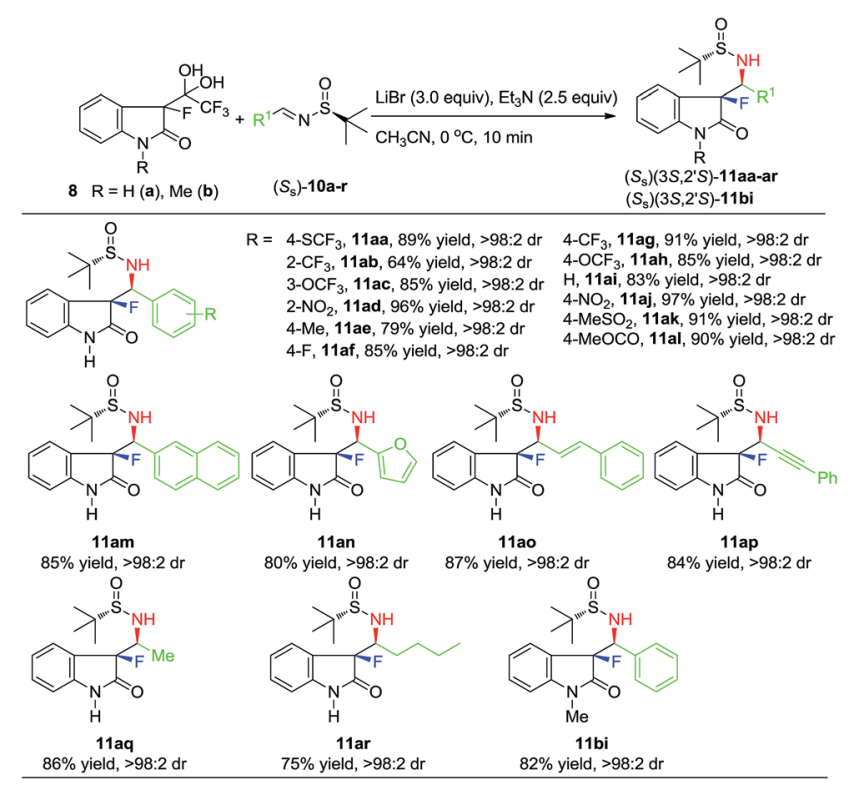

Scheme 2 Substrate generality study of di-ketone hydrates 8 with $\left(S_{\mathrm{s}}\right)-10$. 
$\mathrm{C}=\mathrm{N}$ bond in sulfinylimines $\left(S_{\mathrm{s}}\right)-\mathbf{1 0}$. Generality of this reaction was further exemplified by the preparation of products 11am and 11an, bearing naphthyl and hetero-aromatic rings. Of particular interest were derivatives 11ao and 11ap featuring unsaturated moieties, which can be used for synthetic elaborations. Quite remarkably, this method was found to be readily applicable for enolizable alkyl-aldehyde derived sulfinylimines $\left(S_{\mathrm{s}}\right)-\mathbf{1 0 q}, \mathbf{r}$. Thus, products 11q,r, bearing methyl and $n$-butyl groups, were isolated with the same excellent (>98:2) diastereoselectivity and preparatively attractive chemical yields. Finally, $N$-Me $\beta$-keto-amide-hydrate $\mathbf{8 b}$ was reacted with benzaldehyde derived imine 10i. The addition proceeded without any observable problems giving rise to diastereomerically pure product 11bi with isolated $82 \%$ yield.

$N$-Methyl derivative 11bi was a logical connection to the subsequent second series of substrate generality experiments where we explored the effects of the substituents positioned on the starting $\beta$-keto-amide-hydrates 12 (Scheme 3). Imine $\left(S_{\mathrm{s}}\right)$ 10a, derived from 4-(trifluoromethylthio)benzaldehyde, was selected as standard electrophile and all reactions were conducted under the same conditions. The twelve examples shown in Scheme 3 were selected to represent the two-pronged substituent positioning on the starting di-ketone hydrates 12 . The major conclusion that one can draw from these data, is the synthetically attractive generality of this method, as the nearly perfect diastereoselectivity ( $>98: 2)$ and respected chemical yields of products 13a-l were maintained in all cases studied. Preparation of compounds bearing hydrolytically liable groups (13c), di-substitution (13e) and electronically conjugated $N$-allyl (13k), $N$-phenyl (13l) moieties, deserve some particular mentioning.

As the last synthetic goal of this study we decided to demonstrate the deprotection procedure affording the target compounds with free amino functionality. We selected derivative 11aa, possessing unsubstituted $\mathrm{NH}$ group on the indolin-2one moiety (Scheme 4). The deprotection reaction was

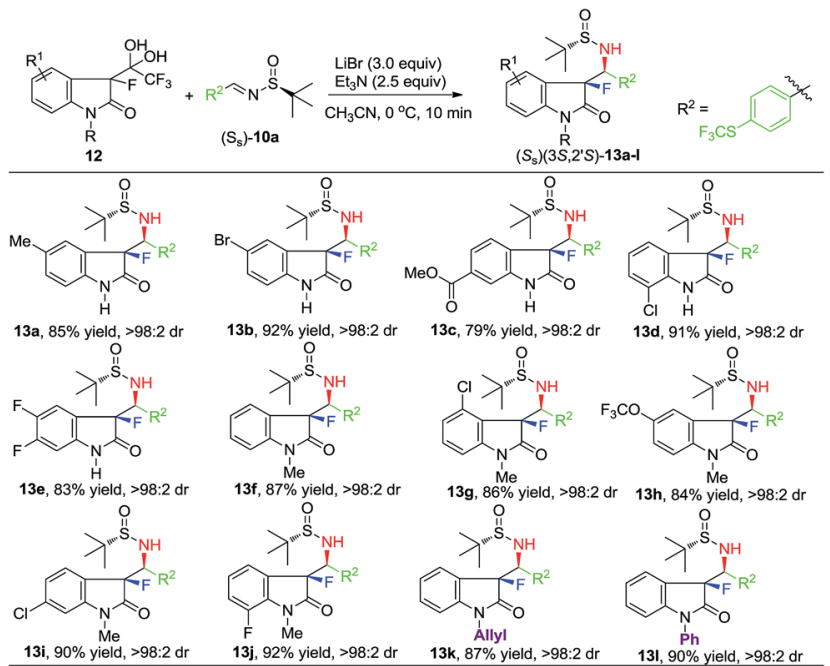

Scheme 3 Substrate generality study of di-ketone hydrates 12 with $\left(S_{s}\right)-10 a$.

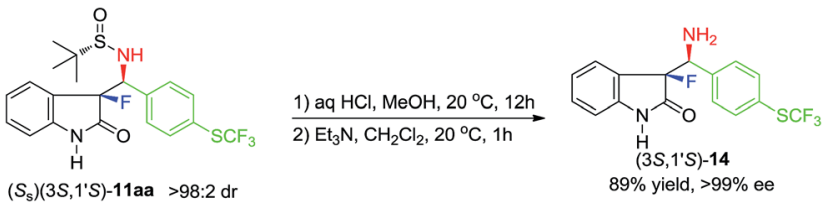

Scheme 4 Deprotection of product $\left(S_{s}\right)\left(3 S, 1^{\prime} S\right)-11 a a$.

conducted under typical mild acidic conditions ${ }^{17}$ giving $\alpha$-fluoro- $\beta$-amino product $\left(3 S, 1^{\prime} S\right)-\mathbf{1 4}$, which was isolated with $89 \%$ yield. Furthermore, product $\mathbf{1 4}$ was found to be of $>99 \%$ ee, strongly suggesting that compounds 11 and 13, listed in Schemes 2 and 3, are virtually diastereomerically pure.

The final objective of this research was the assignment of the absolute configuration of products $\mathbf{1 1}$ and $\mathbf{1 3}$. To this end we performed a crystallographic analysis of $\mathrm{N}$-Me derivative 11bi (Scheme 2), which gave rather unexpected result. Thus, according to the X-ray data (see ESI $\dagger$ ), the configuration of $\mathbf{1 1 b i}$ was found to be $\left(S_{\mathrm{s}}\right)\left(3 S, 2^{\prime} S\right)$, that is in sharp contrast to the $\left(S_{\mathrm{S}}\right)\left(3 S, 2^{\prime} S\right)^{18,19}$ configuration reported for the reactions of $\mathrm{CF}_{3^{-}}$ sufinylimine $\left(S_{\mathrm{s}}\right)-\mathbf{3}$ (Scheme 1).10,14

To rationalize this unexpected stereochemical outcome, we can propose the transition state (TS-A) presented in Fig. 1. First of all, based on the literature data, ${ }^{17}$ the observed $\left(1^{\prime} S\right)$ absolute configuration in products $\left(S_{\mathrm{s}}\right)\left(3 S, \mathbf{2}^{\prime} S\right)-\mathbf{1 1} / \mathbf{1 3}$, strongly suggest that sulfinylimines $\left(S_{\mathrm{s}}\right)$-10 reacts in the corresponding $s$-trans geometric configuration. Furthermore, the $(3 S)$ stereochemistry of the quaternary carbon indicates that sulfinylimines $\left(S_{\mathrm{s}}\right)-\mathbf{1 0}$ approach the re-face of the corresponding tertiary enolates. Taking these experimental facts together, and complying with the principle of minimum charge separation, ${ }^{\mathbf{2 0}}$ we constructed plausible TS-A leading to the products of the observed $\left(S_{\mathrm{s}}\right)\left(3 S, 2^{\prime} S\right)$ absolute configuration. Noteworthy, the close proximity of enolate $\mathrm{O}-\mathrm{Li}$ moiety and the imine nitrogen in TS-A, allows not only for the concerted oxygen-nitrogen charge transfer, but also for the additional stabilization via Li-coordination to the $\mathrm{S}-\mathrm{O}$ oxygen. This feature is never observed in the case of $\mathrm{CF}_{3}$ sulfenylimines 3 (ref. $5 a$ and 10) and may be the underlying reason of the different stereochemical outcome observed in the present study. Moreover, in TS-A the substituent R on the imine, the aromatic ring of the tertiary enolate and $N$-R group are perfectly located to avoid unfavorable overlaps or any other steric interactions. Accordingly, one may agree that TSA can be quite credibly used to elucidate the remarkable substrate generality observed in these Mannich addition reactions.
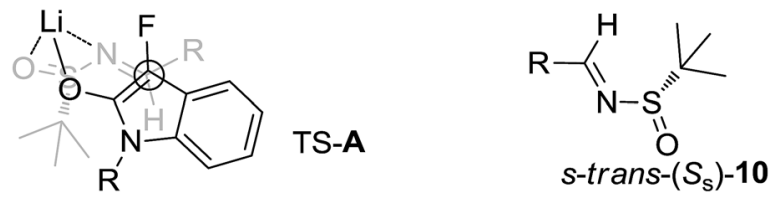

Fig. 1 Plausible transition state TS-A accounting for the observed stereochemical outcome and $s$-trans geometry of sulfinylimines $\left(S_{\mathrm{s}}\right)-10$. 


\section{Conclusions}

In summary, we have developed highly stereoselective detrifluoroacetylative Mannich reactions between the in situ generated tertiary enolates and sulfinyl-imines. The reactions feature nearly complete stereochemical outcome and remarkable generality accommodating several type of functional substitution on both enolates and imines. These reaction characteristics constitute a method of high synthetic value for preparation of enantiomerically pure $\alpha$-fluoro- $\beta$-amino-indolin-2-ones with tetrasubstituted fluorinated stereogenic center.

\section{Acknowledgements}

We gratefully acknowledge the financial support from the National Natural Science Foundation of China (No. 21472082).

\section{Notes and references}

1 (a) Y. Liang, D. Feng, Y. Wu, S.-T. Tsai, G. Li, C. Ray and L. Yu, J. Am. Chem. Soc., 2009, 131, 7792; (b) R. Berger, G. Resnati, P. Metrangolo, E. Weber and J. Hulliger, Chem. Soc. Rev., 2011, 40, 3496.

2 (a) P. Jeschke, ChemBioChem, 2004, 5, 570; (b) T. Fujiwara and D. O'Hagan, J. Fluorine Chem., 2014, 167, 16.

3 (a) Y. Zhou, J. Wang, Z. Gu, S. Wang, W. Zhu, J. L. Aceña, V. A. Soloshonok, K. Izawa and H. Liu, Chem. Rev., 2016, 116, 422; (b) W. Zhu, J. Wang, S. Wang, Z. Gu, J. L. Aceña, K. Izawa, H. Liu and V. A. Soloshonok, J. Fluorine Chem., 2014, 167, 37; (c) J. Wang, M. Sánchez-Roselló, J. L. Aceña, C. del Pozo, A. E. Sorochinsky, S. Fustero, V. A. Soloshonok and H. Liu, Chem. Rev., 2014, 114, 2432; (d) K. Izawa, J. L. Aceña, J. Wang, V. A. Soloshonok and H. Liu, Eur. J. Org. Chem., 2016, 8-16; (e) E. P. Gillis, K. J. Eastman, M. D. Hill, D. J. Donnelly and N. A. Meanwell, J. Med. Chem., 2015, 58, 8315.

4 (a) J. Han, A. E. Sorochinsky, T. Ono and V. A. Soloshonok, Curr. Org. Synth., 2011, 8, 281; (b) K. Mikami, S. Fustero, M. Sánchez-Roselló, J. L. Aceña, V. A. Soloshonok and A. E. Sorochinsky, Synthesis, 2011, 3045; (c) N. Shibata, T. Ishimaru, S. Nakamura and T. Toru, J. Fluorine Chem., 2007, 128, 469; (d) N. Shibata, S. Mizuta and H. Kawai, Tetrahedron: Asymmetry, 2008, 19, 2633; (e) X. H. Xu and F. L. Qiang, Curr. Org. Chem., 2015, 19, 1566.

5 (a) H. B. Mei, C. Xie, J. L. Han and V. A. Soloshonok, Eur. J. Org. Chem., 2016, 5917; (b) X. H. Xu, K. Matsuzaki and N. Shibata, Chem. Rev., 2015, 115, 731; (c) S. Lectard, Y. Hamashima and M. Sodeoka, Adv. Synth. Catal., 2010, 352, 2708; (d) C. Ni, M. Hu and J. Hu, Chem. Rev., 2015, 115, 765; (e) X. Yang, T. Wu, R. J. Phipps and F. D. Toste, Chem. Rev., 2015, 115, 826-870; (f) J. Charpentier, N. Früh and A. Togni, Chem. Rev., 2015, 115, 650; (g) S. Zhang, L. Li, Y. Hu, Y. Li, Y. Yang, Z. Zha and Z. Wang, Org. Lett., 2015, 17, 5036.

6 (a) J. L. Aceña, A. E. Sorochinsky and V. A. Soloshonok, Synthesis, 2012, 1591; (b) K. V. Turcheniuk, V. P. Kukhar, G.-V. Roeschenthaler, J. Luis Acena, V. A. Soloshonok and
A. E. Sorochinsky, $R S C$ Adv., 2013, 3, 6693; (c) X.-L. Qiu and F.-L. Qing, Eur. J. Org. Chem., 2011, 3261.

7 (a) X. Yang, R. J. Phipps and F. D. Toste, J. Am. Chem. Soc., 2014, 136, 5225; (b) N. Mankad and F. D. Toste, Chem. Sci., 2012, 3, 72; (c) R. J. Phipps and F. D. Toste, J. Am. Chem. Soc., 2013, 135, 1268; (d) N. Shibata, J. Kohno, K. Takai, T. Ishimaru, S. Nakamura, T. Toru and S. Kanemasa, Angew. Chem., Int. Ed., 2005, 44, 4204; (e) I. Saidalimu, S. Suzuki, E. Tokunaga, E. Tokunaga and N. Shibata, Chem. Sci., 2016, 7, 2106; (f) W. Yu, X. H. Xu and F. L. Qing, Adv. Synth. Catal., 2015, 357, 2039; (g) Y. Hamashima, K. Yagi, H. Takano, L. Tamas and M. Sodeoka, J. Am. Chem. Soc., 2002, 124, 14530; $(h)$ L. Hintermann and A. Togni, Angew. Chem., Int. Ed., 2000, 39, 4359; (i) H. Ibrahim and A. Togni, Chem. Commun., 2004, 1147.

8 (a) K. Hiramatsu, T. Honjo, V. Rauniyar and F. D. Toste, ACS Catal., 2016, 6, 151; (b) R. J. Phipps, K. Hiramatsu and F. D. Toste, J. Am. Chem. Soc., 2012, 134, 8376; (c) H. P. Shunatona, N. Fruh, Y. M. Wang, V. Rauniyar and F. D. Toste, Angew. Chem., Int. Ed., 2013, 52, 7724; (d) Y. Hamashima, T. Suzukia, H. Takanoa, Y. Shimura and M. Sodeoka, J. Am. Chem. Soc., 2005, 127, 10164; (e) B. M. Trost, T. Saget, A. Lerchen and C. I. Hung, Angew. Chem., Int. Ed., 2016, 55, 781.

9 (a) C. Han, E. H. Kim and D. A. Colby, J. Am. Chem. Soc., 2011, 133, 5802; (b) P. Zhang and C. Wolf, Angew. Chem., Int. Ed., 2013, 52, 7869; (c) I. Saidalimu, X. Fang, X.-P. He, J. Liang, X. Yang and F. Wu, Angew. Chem., Int. Ed., 2013, 52, 5566.

10 H. Mei, C. Xie, J. L Aceña, V. A. Soloshonok, G.-V. Röschenthaler and J. Han, Eur. J. Org. Chem., 2015, 6401.

11 (a) C. Xie, L. Wu, H. Mei, V. A. Soloshonok, J. Han and Y. Pan, Org. Biomol. Chem., 2014, 12, 7836; (b) C. Xie, L. Wu, H. Mei, V. A. Soloshonok, J. Han and Y. Pan, Tetrahedron Lett., 2014, 55, 5908; (c) C. Xie, L. Wu, J. Zhou, H. Mei, V. A. Soloshonok, J. Han and Y. Pan, J. Fluorine Chem., 2015, 172, 13.

12 P. Zhang and C. Wolf, J. Org. Chem., 2012, 77, 8840.

13 (a) C. Xie, L. Wu, J. Han, V. A. Soloshonok and Y. Pan, Angew. Chem., Int. Ed., 2015, 54, 6019; (b) L. Zhang, C. Xie, Y. Dai, H. Mei, V. A. Soloshonok, Y. Pan and J. Han, J. Fluorine Chem., 2016, 184, 28; (c) W. Sha, L. Zhang, W. Zhang, H. Mei, V. A. Soloshonok, J. Han and Y. Pan, Org. Biomol. Chem., 2016, 14, 7295.

14 (a) C. Xie, Y. Dai, H. Mei, J. Han, V. A. Soloshonok and Y. Pan, Chem. Commun., 2015, 51, 9149; (b) C. Xie, L. Zhang, W. Sha, V. A. Soloshonok, J. Han and Y. Pan, Org. Lett., 2016, 18, 3270 .

15 (a) H. Mei, C. Xie, L. Wu, V. A. Soloshonok, J. Han and Y. Pan, Org. Biomol. Chem., 2013, 11, 8018; (b) C. Xie, H. Mei, L. Wu, V. A. Soloshonok, J. Han and Y. Pan, RSC Adv., 2014, 4, 4763; (c) H. Mei, Y. Xiong, C. Xie, V. A. Soloshonok, J. Han and Y. Pan, Org. Biomol. Chem., 2014, 12, 2108.

16 (a) L. M. Wu, C. Xie, H. B. Mei, V. A. Soloshonok, J. L. Han and Y. Pan, Org. Biomol. Chem., 2014, 12, 4620; (b) Y. L. Dai, C. Xie, L. M. Wu, H. B. Mei, V. A. Soloshonok, J. L. Han and Y. Pan, RSC Adv., 2015, 5, 3491. 
17 (a) C. Xie, L. Zhang, H. Mei, R. Pajkert, M. Ponomarenko, Y. Pan, G.-V. Röschenthaler, V. A. Soloshonok and J. Han, Chem.-Eur. J., 2016, 22, 7036; (b) M. T. Robak, M. A. Herbage and J. A. Ellman, Chem. Rev., 2010, 110, 3600. 18 To avoid a confusion, it should be noted that while the descriptors of the absolute configuration for products 11, 13 and those derived from $\mathrm{CF}_{3}$-imine 3 (Scheme 1) are the same, these compounds are stereochemically different due to the Cahn-Ingold-Prelog priority rules ref. 19.
19 R. S. Cahn, C. K. Ingold and V. Prelog, Angew. Chem., Int. Ed., 1966, 5, 385.

20 (a) V. A. Soloshonok, C. Cai, V. J. Hruby, L. V. Meervelt and T. Yamazaki, J. Org. Chem., 2000, 65, 6688; (b) V. A. Soloshonok, H. Ohkura, A. Sorochinsky, N. Voloshin, A. Markovsky, M. Belik and T. Yamazaki, Tetrahedron Lett., 2002, 43, 5445. 